\title{
A Holistic Approach to Estimating the Influence of Good Practices on Student Outcomes at Liberal Arts and non-Liberal Arts Institutions
}

\author{
Brian P. An \\ University of lowa, \\ lowa City, IA, USA \\ brian-an@uiowa.edu \\ Teniell L. Trolian \\ University of lowa, \\ Iowa City, IA, USA \\ teniell-trolian@uiowa.edu
}

\author{
Eugene T. Parker \\ University of Kansas, \\ Lawrence, KS, USA \\ eparker@ku.edu
}

\author{
Dustin D. Weeden \\ National Conference of State \\ Legislatures, Denver, CO, USA \\ dustin.weeden@ncsl.org
}

\begin{abstract}
Many higher education administrators and researchers have considered certain "good practices" of institutions as an instrumental way to improve student outcomes. Chickering and Gamson's (1987) seven principles of good practice has been particularly salient in defining these practices. Often, prior studies only select some of the seven principles for their analysis. Even studies that consider several principles of good practice on student outcomes typically examine the net effect of each principle instead of assessing how these principles holistically influence student outcomes. Using structural equation modeling, we test a basic conceptual framework where we investigate the contribution of the seven principles on a global measure of good practices (GP), as well as the influence of GP on a multitude of student outcomes. We further test whether liberal arts colleges promote an institutional ethos of good practices as compared to non-liberal arts colleges. Overall, the majority (but not all) of the principles affect GP. Moreover, we find partial evidence that liberal arts colleges foster an institutional ethos of good practices. Although a commitment to foster good practices may create a supportive environment that influences student outcomes, this commitment may lead to unintended consequences for those with little exposure to these good practices.
\end{abstract}

Material published as part of this publication, either on-line or in print, is copyrighted by the Informing Science Institute. Permission to make digital or paper copy of part or all of these works for personal or classroom use is granted without fee provided that the copies are not made or distributed for profit or commercial advantage AND that copies 1) bear this notice in full and 2) give the full citation on the first page. It is permissible to abstract these works so long as credit is given. To copy in all other cases or to republish or to post on a server or to redistribute to lists requires specific permission and payment of a fee. Contact Publisher@,InformingScience.org to request redistribution permission.
Keywords: good practices, learning outcomes, student experiences, liberal arts colleges, liberal arts education, Wabash National Study

\section{Introduction}

How colleges affect student outcomes are an important line of inquiry for higher education administrators and researchers, where they have considered

\section{Peer Blind Reviewed Research Article \\ Editor: Jean M Henscheid}

Submitted: December 17, 2015; Revised: February 20, 2016; Accepted: April 13, 2016 
certain "good practices" of institutions that improve student outcomes. Perhaps the best known manifestations of good practices are derived from Arthur Chickering and Zelda Gamson's work (1987), in which they propose seven principles of good practice: student-faculty contact, cooperation among students, active learning techniques, prompt feedback to students, time on task, high expectations, and respect for diverse talents and ways of learning. Studies show that the principles of good practice lead to educational gains (Cruce, Wolniak, Seifert, \& Pascarella, 2006; Pascarella, Wolniak, Cruce, \& Blaich, 2004; Seifert, Pascarella, Goodman, Salisbury, \& Blaich, 2010). Moreover, higher education researchers are interested in the ways in which good practices reduce (or exacerbate) inequities across social groups (Seifert, Gillig, Hanson, Pascarella, \& Blaich, 2014).

However, researchers often consider these seven principles separately or they consider the independent effect of each principle on student outcomes. An exception is Cruce et al.'s (2006) study where they use a global measure of good practices; but, they construct their global measure without assessing which principles contribute to good practices. Still unknown is which principles affect good practices as a general construct and whether the influence of good practices differs between liberal arts and non-liberal arts colleges.

In this study, we test Chickering and Gamson's (1987) seven principles of good practice in undergraduate education. Few researchers consider these seven principles in a holistic way (hereafter GP). As a result, past studies are unable to parse out the global influence of the seven principles together as a group from the unique effects of each of the seven principles on student outcomes. In doing so, we are able to identify which of the seven principles contribute to GP; not all seven principles may uniquely influence GP. We further examine the extent to which the seven principles occur at liberal and non-liberal arts colleges. Given the reputation of liberal arts colleges for low student-to-faculty ratios, more individualized attention, and more opportunities for research, we expect that these colleges exert an institutional ethos that fosters good practices.

Moreover, we expect that students at liberal arts colleges are exposed to good practices at higher rates than those at non-liberal arts colleges (Cruce et al., 2006; Pascarella et al., 2004). Finally, we expect that the influence of GP on college outcomes is stronger at liberal arts than non-liberal arts colleges.

\section{Literature Review}

\section{Defining the Seven Principles of Good Practice}

Based on a fifty-year review of research, Chickering and Gamson (1987) propose seven guiding principles of teaching and learning in colleges and universities. Student-faculty contact involves both in- and out-of-class contact with faculty, which fosters students' motivation and academic engagement. Reciprocity and cooperation among students encourage students to engage in learning as a social process by promoting teamwork. Active learning encourages students to discuss with others what they are learning and to connect what they are learning with past experiences. Prompt feedback entails providing students with appropriate and timely feedback on their performance. Time on task involves defining appropriate expectations for how students spend time on academic endeavors both in and out of the classroom. High expectations encourage students to perform at a high level. Finally, respecting diverse talents and ways of learning acknowledges and provides for the multiple ways in which students engage the learning process.

Chickering and Gamson (1987) developed these seven principles to serve as guidelines for colleges and to encourage improvement of undergraduate teaching and learning based on these foundational ideas. They further note that, although each principle separately is important for teaching and learning, the presence of all principles multiplies the effect. Cruce et al. (2006) cor- 
roborate this assertion where they find that the relation between the principles of good practice and several cognitive and noncognitive outcomes is stronger when good practices are assessed holistically rather than separately.

Building on Chickering and Gamson's (1987) work, researchers have investigated students' experiences with and exposure to the principles of good practice. For instance, active learning and cooperation among students led to academic gains in their general education and intellectual skills (Kuh, Pace, \& Vesper, 1997). Research further shows a positive relation between academic effort and perceived educational gains (Ethington, 2000). In fact, research lends support for each principle of good practice on a host of student outcomes (Chickering \& Reisser, 1993; Cruce et al., 2006; Pascarella \& Terenzini, 2005).

\section{The Role of a Liberal Arts Education and Liberal Arts Colleges in Cultivating Good Practices}

Several researchers further consider the relation between good practices and attendance at a liberal arts college (Cruce et al., 2006; Pascarella et al., 2004; Seifert et al., 2010). It makes sense for researchers to consider differential effects of the principles of good practice by institution type because these principles interact best in settings where the institution makes concerted efforts to create a supportive environment that enhances student outcomes (Cruce et al., 2006; Pascarella \& Terenzini, 2005). One such effort is institutions that adhere to a liberal arts education. The Center of Inquiry, a research center dedicated to evidence-based policy and practices that strengthen a liberal arts education, defines a liberal arts education as one that centers around an institutional ethos of intellectual inquiry and critical thinking rather than professional or vocational development, an environment and curriculum that promote intellectual growth, and a culture where peer and faculty interactions both in and out of the classroom are the norm (Blaich, Bost, Chan, \& Lynch, 2004).

Collectively, a liberal arts education instills learning outcomes that extend beyond mere academic performance but rather cultivates the individual into becoming an informed citizen (King, Brown, Lindsay, \& Vanhecke, 2007). For example, the National Leadership Council for Liberal Education and America's Promise (2007) argues for learning outcomes of a liberal education that are essential in a global society: "rich knowledge, higher-level skills and creativity, social responsibility, examined values, and the ability to apply learning to complex and problems" (p. 14).

It is important to note that a liberal arts education is not the same as a liberal arts college. A liberal arts education represents the pedagogies, goals, and accomplishments in higher education that instill a particular type of college experience (Blaich et al., 2004). By contrast, a liberal arts college refers to a particular type of higher education institution. Therefore, the presence of a liberal arts education may exist in non-liberal arts colleges and a liberal arts education may be absent at some liberal arts colleges.

Despite this potential lack of correspondence, advocates contend that liberal arts colleges provide optimal conditions for these principles to strive (Astin, 1999; Hersh, 1999; Pascarella, Wolniak, Seifert, Cruce, \& Blaich, 2005). Faculty members at liberal arts colleges tend to have different orientations toward teaching compared to those at research universities. Smaller class sizes and a smaller overall student population at liberal arts colleges provide students with fewer lectures and more opportunities to engage in active learning (Cech, 1999; Hersh, 1999; Pascarella et al., 2005). Although many professors at research universities enjoy teaching, research is their primary focus. By contrast, faculty members are rewarded more for teaching than research at liberal arts colleges (Cech, 1999; Freeman, 2002; Hughes, 2014). Additionally, many liberal arts colleges do not have graduate programs, which provide undergraduates the opportunity to work on research projects independently or with faculty (Hersh, 1999; Stimpert, 2004). As a result, faculty at liber- 
al arts colleges tend to put more effort into teaching and provide greater access to students than faculty at research universities, especially outside of the classroom (Astin, 1999; Cech, 1999; Stimpert, 2004). These benefits of liberal arts colleges are likely to foster meaningful studentfaculty contacts among undergraduate students (Howell \& Eidson, 1985).

Research shows that attendance at liberal arts colleges is positively associated with psychological well-being, leadership development, openness to diversity, and inclination to inquire (Seifert et al., 2008). Moreover, students at liberal arts colleges tend to exhibit greater gains in their need for cognition than those at research universities. In particular, the influence of liberal arts colleges on cognitive growth operates through classroom instruction and students' deep approaches to learning (Pascarella, Wang, Trolian, \& Blaich, 2013).

Researchers have further investigated the link between liberal arts colleges, and students' cultural awareness and social responsibility. Students at liberal arts colleges are more likely to participate in diversity-related activities than those at non-liberal arts colleges (Umbach \& Kuh, 2006). Although $\mathrm{Hu}$ and $\mathrm{Kuh}$ (2003) find that the benefits of interactional diversity experiences are similar regardless of institution types, in general, the effect of interactional diversity experiences on two outcomes - science and technology, and intellectual development-is greater for white students than minority students at liberal arts colleges.

It is not surprising then that students at liberal arts colleges tend to have greater exposure to the principles of good practice than those at non-liberal arts colleges (Pascarella et al., 2004). For example, Seifert et al. (2010) estimate that good teaching and high-quality interactions with faculty are 0.50 standard-deviations higher at liberal arts colleges than at research universities, and students at a liberal arts college experience a 0.34 standard-deviation advantage in academic challenge and high expectations over those at a research university. The advantage in exposure to these good practices remains, albeit lower (0.26-0.28 standard deviations), when they compare between liberal arts colleges and regional institutions. Seifert et al. (2010) further show that students most in need of good practices - those in the lower distribution of socioeconomic status (SES), academic achievement, and motivation - experience greater levels of good practices at liberal arts colleges. Liberal arts colleges may therefore lead to compensatory effects for students underprepared for college.

\section{The Need for Continued Research on Good Practices}

Despite substantial research showing positive effects of good practice principles on student outcomes, previous research is limited in five ways. First, prior research tends to select specific principles of good practice without considering all seven principles at once. Second, prior research tends to limit the sample to a single or few postsecondary institutions. Third, studies tend to examine the immediate influence of good practice principles on student outcomes (e.g., first year of college) instead of the longer-term influence of these principles. Fourth, prior studies often do not include outcome premeasures and instead rely on self-reported gains.

The fifth limitation is that although Chickering and Gamson (1987) contend that the influence of good practice principles on student outcomes multiplies as students experience more principles, few studies have holistically tested all seven principles on student outcomes. Even studies that consider several principles of good practice on student outcomes tend to examine the net effect of each principle instead of confirming these principles as influencing a global concept of good practices. Typically, researchers use a multiple regression approach to estimate the principles of good practice on an outcome (or outcomes). This approach shows the association between a specific good practice principle and a student outcome, controlling for other principles. This type of model specification addresses a certain type of research question, which is "what is the unique effect of each good practice principle on student outcomes?" 
However, researchers often discuss good practices in a more general sense, that is, "do good practices of teaching and learning influence student outcomes?" Researchers should not consider the principles of good practice separately but rather holistically to form a challenging and supportive campus environment for a student's development (Seifert et al., 2010). Unlike in previous research - where each principle of good practice exerts an effect on a student outcome, controlling for other principles - we propose that the principles directly influence a global composite of good practices (GP). Therefore, we are able to estimate the unique contribution of each principle on GP. In turn, GP, and not the principles, affect student outcomes (see Appendix A for a further illustration of this point).

Our study is conceptually similar to the one Cruce et al. (2006) conducted in that they consider not only the influence of good practice subscales on a host of student outcomes, but a global measure of good practices as well. They find that good practice subscales exert a positive influence on students' learning, critical thinking, and college experiences. However, their global measure of good practices exerts a stronger influence on student outcomes than any good practice subscale, suggesting shared variance among the good practice subscales on student outcomes. Interestingly, Cruce et al. (2006) show that students at non-liberal arts colleges may benefit more from good practices than those at liberal arts colleges. This result differs from Pascarella et al.'s (2004) work where they find that the influence of good practices on student outcomes is stronger at liberal arts colleges than at non-liberal arts colleges. Nevertheless, Cruce et al. (2006) and Pascarella et al. (2004) suggest that liberal arts colleges subscribe to an institutional ethos that fosters good practices where students at these colleges receive greater exposure to a host of good practice principles.

Cruce et al. (2006) are among the first to consider empirically good practices as a global concept. We expand on Cruce et al.'s (2006) study in three ways. First, Cruce et al. (2006) create the global measure of good practices without specifying how each principle or subscale contributes to good practices. By contrast, we simultaneously estimate the construction of GP (through its seven principles) and the effect of GP on multiple student outcomes. We are able to determine whether all seven principles or a subset of these principles influence GP. Second, we include multiple outcomes simultaneously, which differs from prior studies. Third, unlike Cruce et al. (2006), where they examine first-year student outcomes, we consider fourth-year outcomes in which students have longer exposure to GP.

In our study, we consider all seven principles of good practice at once and estimate the contribution of each principle to GP. We further estimate the influence of GP on multiple student outcomes. Moreover, we assess whether the effects of GP differ between liberal arts and non-liberal arts colleges. The goal of this study is to expand our understanding of the principles of good practice, whether it is feasible to think of good practices globally or whether we need to keep each principle separate. Four questions guide our study: (1) Do the seven principles of good practice contribute to GP? (2) Is an institutional ethos that fosters GP more likely to occur at liberal arts colleges than at non-liberal arts colleges? (3) Does GP improve student outcomes? (4) Within institution type, does the influence of GP differ by race, gender, and academic achievement?

\section{Data and Methods}

We use data from the Wabash National Study of Liberal Arts Education (WNSLAE), a longitudinal study of first-time college students who entered one of seventeen postsecondary schoolseleven liberal arts colleges and six universities - in fall 2006. The main purpose of the WNSLAE is to examine factors that influence student outcomes related to a liberal arts education (Center of Inquiry at Wabash College, 2011). These institutions are located at the Northeast, Southeast, Midwest, and West regions of the United States. Investigators resurveyed students in spring 2006 and again in spring 2010. Importantly, investigators administered the National Survey of Student 
Engagement and the Student Experiences Survey to assess students' experiences with the principles of good practice in spring 2006 and 2010. Among the 4,193 students who participated in the fall 2006 baseline survey, 2,212 students completed both the fall 2006 and spring 2010 assessments. However, investigators randomly assigned half of the respondents to take either a criticalthinking (which we use) or a moral-reasoning test. As a result, our analytical sample is 1,065 students.

\section{Dependent Variables}

We include six student outcomes for our analysis, which are taken from spring 2010. These outcomes are consistent with past research that considers students who experience a liberal arts education are expected to develop in several key areas that helps them become informed citizens essential in a global society (King et al., 2007; National Leadership Council for Liberal Education and America's Promise, 2007; Seifert et al., 2008). Three outcomes capture a student's cognitive development and inclinations (see Appendix B for variable description and summary statistics). Two outcomes capture a student's interests, attitudes, and behaviors toward diversity of others, and one outcome captures a student's leadership development. Need for cognition, attitude towards literacy, and critical thinking measure a student's cognitive development and inclinations. Need for cognition (18 items; alpha $=0.89)$ assesses the extent to which a student enjoys engaging in cognitive activities (readers interested in further information about the outcomes, see Center of Inquiry at Wabash College, 2011). Attitude towards literacy (6 items; alpha $=0.71)$ measures a student's enjoyment of reading and writing. To measure critical thinking, we use the Collegiate Assessment of Academic Proficiency critical thinking test (CTT). Developed by ACT, the CTT is a 40-minute, 32-item test that assesses a student's ability to analyze, evaluate, and extend arguments.

Orientation towards diversity and openness to diversity measure a student's interests, attitudes, and behaviors toward diversity of others. The Miville-Guzman Universality-Diversity scale (MGUD; alpha $=80$ ) captures a student's universal diverse orientations, which represent the student's awareness of similarities and differences of others. Openness to diversity ( 7 items; alpha $=$ 0.87 ) includes the extent to which a student enjoys being challenged by others with different perspectives. The Socially Responsible Leadership scale (SRLS; alpha $=0.84$ ) assesses a student's leadership along several leadership elements: consciousness of self, congruence, commitment, common purposes, collaboration, change and controversy with civility and citizenship.

\section{Principles of Good Practice}

Several indicators capture the seven principles of good practice (see Appendix C for list of items used to create each principle). (1) Student-faculty contact ( 15 items; alpha $=0.90)$ captures positive interactions between students and faculty. (2) Cooperation among students (4 items; alpha = 0.68 ) represent the extent to which students learn from one another. (3) Active learning (7 items; alpha $=0.73$ ) captures how students make connections to learning. (4) Prompt feedback (3 items; alpha $=0.68)$ represents appropriate and timely faculty feedback on students' learning performance. $(5)$ Time on task (10 items; alpha $=0.73)$ captures appropriate expectations for how students spend time on academic activities and endeavors. (6) High expectations ( 7 items; alpha = 0.82 ) are the extent to which students are encouraged to perform academically at a high level. Finally, three binary indictors capture (7) respect towards diverse talents and ways of learning: completed independent study or a self-designed major; completed a practicum, internship or clinical assignment; and worked on a research project with a faculty member. 


\section{Control and Moderating Variables}

We include several precollege indicators in our models. Gender is a binary indicator, female or male, where male students are the reference category. Race is also a binary indicator where underrepresented minority students are coded as 1 (black, Hispanic, and Native American). Therefore, white and Asian students are the reference category. Parental education is represented as two binary indicators where at least one parent attained a bachelor's degree or a post-bachelor's degree (less than a bachelor's degree is the reference category). Composite ACT scores capture a student's precollege academic achievement. We further control for whether a student received financial aid. Initial major aspiration represents whether a student intended to major in liberal arts during fall 2006. In addition to initial major aspiration, we include a student's major or intended major in the liberal arts by the fourth year of college. Precollege academic motivation ( 8 items; alpha $=0.69)$ captures a student's intrinsic motivation to complete academic tasks (Gillig, Roksa, \& Pascarella, 2013).

A strength of the WNSLAE is that it contains premeasures of all outcomes in our study. Outcome premeasures serve as powerful controls because they establish a student's knowledge base prior to college exposure. A critical-thinking premeasure, for example, captures the cumulative effects of a student's family, peer, community, and schooling experiences on critical thinking at the beginning of college (Hanushek, Kain, \& Rivkin, 2009). Therefore, including outcome premeasures allow us to state more confidently that the influence of good practices on college outcomes is due more to what happens in college than to individual baseline differences (Padgett, Salisbury, An, \& Pascarella, 2010).

We include institutional fixed effects as additional controls. Fixed effects models control for stable institutional characteristics, meaning that institutions serve as their own controls (Allison, 2009). Despite using within-institution variation to estimate the effects of college experiences, we are able to estimate separately path models between those at liberal arts colleges and those at nonliberal arts colleges. Furthermore, we constrain the paths across institution types to assess whether the path coefficient is the same or different across types.

\section{Methods}

We use structural equation modeling (SEM) to estimate the influence of GP on cognitive development, diversity, and leadership development. SEM allows us to specify and test a causal process under study as a series of structural equations. We are able to test globally the entire system of variables to examine the extent the model specification reasonably represents the data. Moreover, SEM allows us to fit simultaneously structural equations for those at liberal arts and nonliberal arts colleges, and it allows us to test for equality in paths across groups (Acock, 2013).

SEM is particularly useful for our analysis, because we specify both reflective and formative measurement models (for an implementation of this approach, see Hauser, Tsai, \& Sewell, 1983). In a reflective model, direction of causality moves from the latent construct to the observed variables. In a formative model, by contrast, the direction of causality moves from the observed variables to the latent composite variable. The effect indicators in a reflective model should be internally consistent and interchangeable for equally reliable measures of a unidimensional construct; but this requirement is not necessary for formative indicators (Kline, 2006). Therefore, we do not assume that the seven principles are caused by a unidimensional factor (reflective model), but rather that all seven principles influence GP (formative model).

Although reflective models are the most common specification used in SEM, it is not always suitable to think of observed indicators as reflective of an underlying construct. For example, SES is typically comprised of parents' education, parents' occupation, and family income. In a reflective model, these variables are caused by an underlying socioeconomic factor. It is, however, more 
appropriate to think of SES as determined by the observed indicators (Hauser et al., 1983; Kline, 2006). Similarly, it is unclear from the literature whether the seven principles reflect an underlying good practice. The goal of the study is to specify a latent composite of GP-where GP is determined by the seven principles based on Chickering and Gamson's (1987) seminal piece - and consider whether GP affects student outcomes. With this approach, we are able to assess which of the seven principles directly influence GP.

\section{Results}

We begin with three model specifications and assess each model's fit (Table 1). Similar to prior studies, we allow for each of the good practice principles to affect each of the student outcomes in model 1 . In model 2, we consider a latent composite (GP) that is derived from the seven principles and GP in turn affects the student outcomes. Model 3 is similar to model 2 with one key difference. Unlike in model 2 where we estimate the disturbance of GP, we do not estimate this disturbance in model 3. Under this specification, GP is a linear combination of the observed variables and it is not influenced by variables other than the seven principles (Bollen \& Bauldry, 2011).

Table 1. Fit Statistics of Structural Models

\begin{tabular}{lrrrr}
\hline & & \multicolumn{3}{c}{ Composite of good practices (GP) } \\
\cline { 3 - 5 } Fit statistics & No GP & Estimate error & Error set 0 & Preferred \\
\hline Chi-Square & Model 1 & Model 2 & Model 3 & Model 4 \\
Degrees of freedom (DF) & 697.26 & 342.51 & 806.73 & 350.99 \\
Bayesian Information Criterion (BIC) & 92 & 170 & 172 & 181 \\
Root Mean Square Error of Approximation (RMSEA) & 0.11 & 0.04 & 0.08 & 0.04 \\
Comparative Fit Index (CFI) & 55.95 & -842.52 & -392.24 & -910.71 \\
Tucker-Lewis Index (TLI) & 0.91 & 0.98 & 0.91 & 0.98 \\
& 0.34 & 0.90 & 0.63 & 0.91 \\
\hline
\end{tabular}

Note: WNSLAE 2006. Sample size is 1,065 respondents

Model 1 fits the data poorly. For example, a negative statistic in the Bayesian Information Criterion (BIC) denotes a good fit. However, the BIC statistic for model 1 is positive. Moreover, other fit indices, such as the RMSEA, CFI, and TLI miss targeted values (Mueller \& Hancock, 2010). Therefore, we find little support for a model where the principles of good practice are estimated freely on cognitive development, diversity, and leadership development.

Among the three model specifications, model 2 provides the best fit of the data. Recall that model 2 specifies GP as deriving from the seven principles, and GP in turn influences cognitive development, diversity, and leadership development. Furthermore, model 2 estimates the GP disturbance whereas model 3 does not. The BIC difference between model 1 and 2 is 898 in favor of model 2. Similarly, the BIC difference between model 2 and model 3 is 450 in favor of model 2. Raftery (1995) suggests a BIC difference of 10 as very strong evidence to favor one model over another model. Because the BIC statistic favors model 2 over models 1 and 3, we use model 2 as our starting point. Other fit indices further corroborate that model 2 provides a good fit. In particular, the RMSEA (0.04) and CFI (0.98) meet targeted values (Mueller \& Hancock, 2010).

Model 2 allows for all paths to estimate freely. As previously mentioned, SEM allows for equality constraints of path coefficients across institution types. In other words, we are able to test for- 
mally whether the effect of GP on critical thinking, for example, is the same for those at a liberal arts and non-liberal arts college. Due to the number of estimated paths and possible equality constraints across institution type, race, gender, and prior academic achievement, we simplify the modeling process where we first allow all paths to estimate freely (as in model 2). We then impose equality constraints of the paths from the principles of good practice to GP as well as the paths from GP to student outcomes. Of course, this means that we estimate paths that are not statistically significant, which lessens the model's overall fit. However, in preliminary analyses (not shown), we found that removing statistically insignificant paths from control variables to the principles of good practice did not alter substantively the influence of the principles on GP. We therefore allow all paths to estimate freely with the exception of paths that are substantively relevant for our analysis, that is, paths from the principles of good practice to GP and the paths from GP to student outcomes. Model 4 of Table 1 shows fit statistics of our preferred specification.

Table 2. Unstandardized and Standardized Effects of Seven Principles on GP

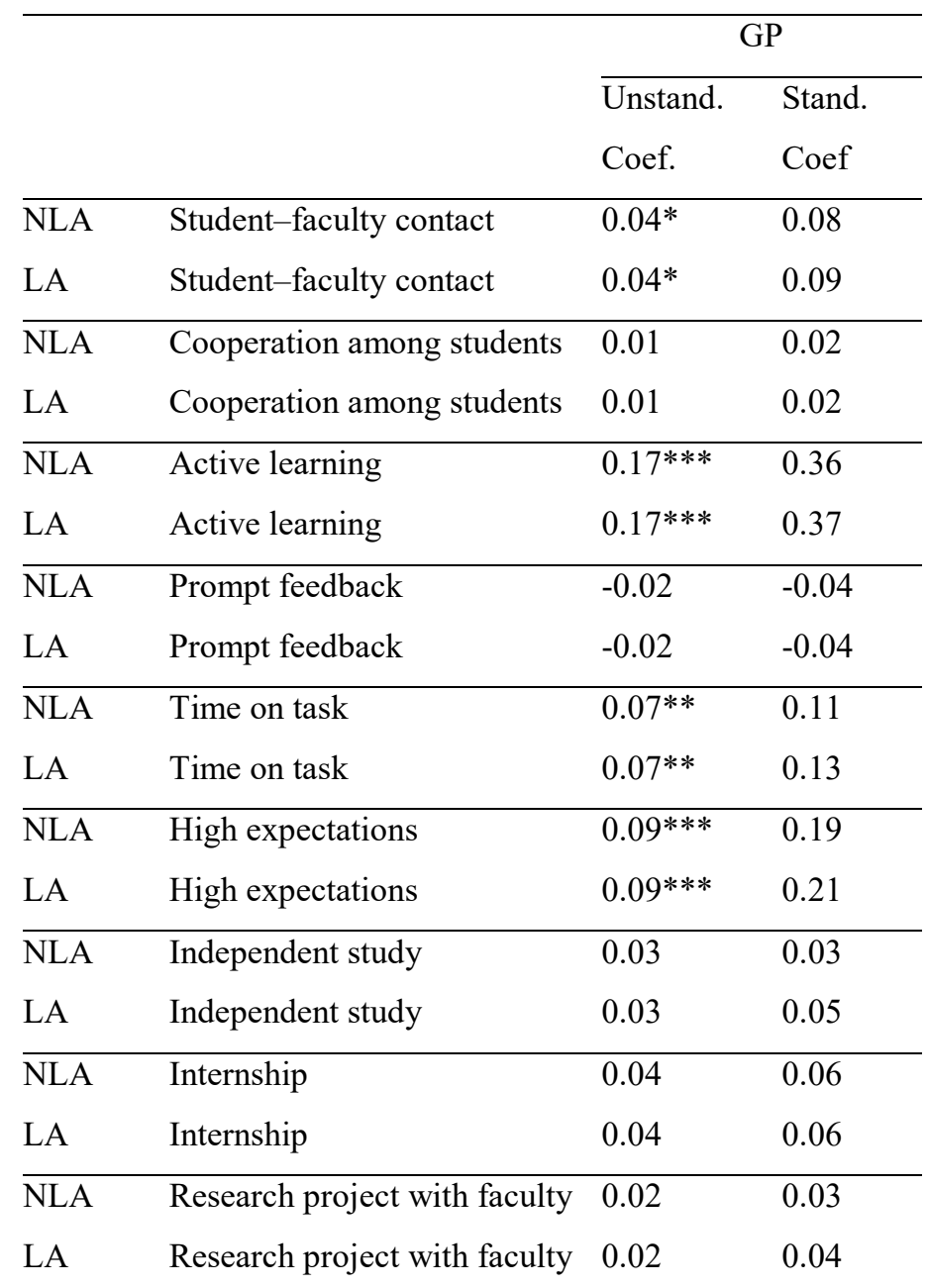

Note: WNSLAE 2006. Sample size is 1,065 respondents. ${ }^{*} p<0.05,{ }^{* *} p<0.01$, $* * * p<0.001$ (two-tailed). NLA $=$ Non-liberal arts college. $\mathrm{LA}=$ Liberal arts college 


\section{Question 1: Do the Seven Principles Contribute to Good Practices (GP)?}

We now turn to the estimated path coefficients in Table 2. We find support that the principles of good practice contribute to GP (question 1), although our finding requires a caveat. If we enforce a strict criterion in which all seven principles must contribute to GP, then there is little support that the principles affect GP. However, if we relax this strict criterion and instead state that a majority of the principles need to affect GP, then four of the seven principles influence GP. For both institution types, active learning exerts the strongest influence on GP, followed by high expectations. In addition, student-faculty contact and time on task influence GP. There is little evidence that cooperation among students and prompt feedback from faculty significantly affect GP. Moreover, none of the three indicators that represent respect towards diverse talents and ways of learning influence GP. This does not suggest that cooperation among students, for example, has no influence on student outcomes, but rather that cooperation among students does not contribute significantly to the construction of GP.

\section{Question 2: Is an Institutional Ethos that Fosters GP more likely to occur at Liberal Arts Colleges than at Non-Liberal Arts Colleges?}

The evidence is mixed of an institutional ethos promoting good practices at liberal arts colleges (question 2). Inconsistent with an institutional ethos explanation, the number of good practice principles affecting GP is the same across institution type. Furthermore, the influence of the principles on GP is the same across institution type. The model's fit does not significantly differ when we impose equality constraints on the path coefficients of principles on GP across institution type.

\begin{tabular}{ll}
$\begin{array}{c}\text { Table 3. OLS Regression of Liberal Arts Colle } \\
\text { on Principles of Good Practice }\end{array}$ \\
\hline Principles of good practice & $\begin{array}{l}\text { Liberal arts } \\
\text { colleges }\end{array}$ \\
\hline Student-faculty contact & $0.40^{* * *}$ \\
Cooperation among students & 0.07 \\
Active learning & $0.16^{* * *}$ \\
Prompt feedback & $0.41^{* * *}$ \\
Time on task & $0.20^{* * *}$ \\
High faculty expectations & $0.31^{* * *}$ \\
Independent study & $0.17^{* * *}$ \\
Internship & $0.13^{* * *}$ \\
Research project with faculty & $0.09^{* *}$ \\
Composite of good practices & $0.36^{* * *}$ \\
Controls & See Note
\end{tabular}

Note: WNSLAE 2006. Sample size is 1,065 respondents. All analyses control for gender, race, parental education, ACT scores, financial aid, initial major aspiration, pre-college academic motivation, and outcome premeasures. ${ }^{*} p<0.05,{ }^{*} p<0.01, * * * p<0.001$ (two-tailed) 
Despite these findings, there is evidence consistent with an institutional ethos explanation. In supplemental analysis, we estimate the influence of liberal arts colleges on good practices (Table 3 ). Students at liberal arts colleges tend to exhibit higher levels of good practice principles than students at non-liberal arts colleges. These results hold even after accounting for precollege controls. The exception is that students tend to cooperate with other students similarly between liberal arts and non-liberal arts colleges.

Further consistent with an institutional ethos explanation, the influence of GP on students' orientation towards diversity, openness to diversity, and leadership development are stronger at liberal arts colleges than at non-liberal arts colleges (see Table 4). The model fits the data poorly when we impose equality constraints from GP to each of these three outcomes across institution type. However, the influence of GP on need for cognition, positive attitude towards literacy, and critical thinking does not differ across institution type.

\section{Question 3: Does GP improve Student Outcomes?}

Nevertheless, GP positively influences all six student outcomes in our model (question 3). For example, a standard-deviation increase in GP increases students' need for cognition by $0.47-0.53$ standard deviations. Overall, a standard-deviation increase in GP is positively associated with 0.30-0.60 standard-deviations increase in cognitive development, diversity, and leadership development. The exception is that GP exerts a marginal influence on critical thinking ( 0.10 standard deviations or less).

Table 4. Unstandardized and Standardized Effects of GP on College Experiences (with Equality Constraints across Institution Type for all Principles of Good Practice on GP)

\begin{tabular}{llllllll}
\hline & & \multicolumn{7}{c}{ Dependent Variables } \\
\cline { 3 - 7 } & Predetermined & Need for & & Orientation & Open & Attitude & Critical \\
& Variables & Cognition & Leadership & Diversity & Diversity & Literacy & Thinking \\
\hline NLA & Good Practice & 1.00 & $0.67^{* * *}$ & $0.90^{* * *}$ & $1.09^{* * *}$ & $0.80^{* * *}$ & $1.20^{* * *}$ \\
& Standardized & 0.53 & 0.56 & 0.46 & 0.50 & 0.32 & 0.10 \\
\hline LA & Good Practice & 1.00 & $0.92^{* * *}$ & $1.36^{* * *}$ & $1.54^{* * *}$ & $0.80^{* * *}$ & $1.20^{* * *}$ \\
& Standardized & 0.47 & 0.59 & 0.58 & 0.60 & 0.30 & 0.06
\end{tabular}

Note: WNSLAE 2006. Sample size is 1,065 respondents. ${ }^{*} p<0.05,{ }^{* *} p<0.01,{ }^{* * *} p<0.001$ (two-tailed). NLA $=$ Non-liberal arts school. LA $=$ Liberal arts school

\section{Question 4: Within Institution Types, does the Influence of GP differ by Race, Gender, and Academic Achievement?}

Finally, we assess whether the influence of GP differs by race, gender, and academic achievement (question 4). For each group, we divide the sample into four subgroups. Using gender as an example, the four subgroups are males at liberal arts colleges, females at liberal arts colleges, males at non-liberal arts colleges, and females at non-liberal arts colleges. For academic achievement, a continuous measure, we create a dichotomous indicator where individuals are above or below the mean in ACT. However, we include students' ACT scores in the structural model to account for the correlations among ACT scores and other independent variables. We find little evidence that the influence of GP differs by group and institution type (results not shown but available upon request). The exception is that the influence of GP on orientation towards diversity is stronger for male students at non-liberal arts colleges $(\beta=1.53)$ than female students at similar colleges $(\beta=$ $0.69)$. 


\section{Limitations}

Common to all studies, our study has limitations. Although the WNSLAE includes several institution types from multiple regions, the results may not generalize to the United States. Given that a major purpose of the WNSLAE is to estimate the influence of liberal arts colleges and liberal arts education on student outcomes, investigators oversampled liberal arts colleges for the WNSLAE. A consequence of this sampling strategy is that the sample tends to have students and institutions with characteristics above that of a typical undergraduate institution. In particular, our sample contains a higher proportion of white students than the national average. Despite this oversample of liberal arts colleges, over $40 \%$ of the students attend mid-selective institutions. This implies that our results are not estimated solely among those who attend selective colleges.

\section{Discussion}

Studies that examine the influence of the principles of good practice on student outcomes often examine the net effects of each principle on an outcome. Although researchers emphasize the interconnected nature of good practices, most research instead considers principles as independent levers. Often researchers are interested in the effect of a particular principle when "activated," that is, when students are exposed to the principle. Our study calls for an agenda that provides conceptual guidance of how the seven principles of good practice holistically influence a student's undergraduate education. We test a basic conceptual framework where we investigate the contribution of the seven principles together to a global concept of good practices (GP), as well as the influence of GP on a multitude of student outcomes. Although not the only way to conceive of good practices, we reason that these principles that higher education researchers and educators advocate as good practices should contribute to an overarching concept of good practices.

It is surprising that Cruce et al. (2006) is the only study of which we are aware that has considered the global effect of good practices on student outcomes. Our study follows this line of inquiry in that we consider GP on student outcomes. Consistent with Cruce et al. (2006), we found GP has a positive effect on several student outcomes, such as openness to diversity, positive attitude towards literacy, and critical thinking skills. We further found positive effects of GP that Cruce et al. (2006) did not analyze but are nonetheless important for a liberal arts education. These include socially responsible leadership, orientation towards diversity, and need for cognition. One concerning finding was that GP exerts only a modest effect on critical thinking. A standard-deviation increase in GP increased critical thinking by 0.10 standard deviations or less. This result is consistent with Arum and Roksa's (2011) finding that gains in critical thinking are modest in college. Aside from critical thinking, however, GP raises other learning dimensions at a greater rate, between 0.30 and 0.47 standard deviations.

In addition to these main effects of GP, our study is the among the first that tests whether liberal arts colleges instill an institutional ethos that fosters good practices. If an institutional ethos of good practices exists at liberal arts colleges, then certain relationships are more likely to occur at a liberal arts college than at a non-liberal arts college. In our study we contended that there are three ways in which liberal arts colleges instill an institutional ethos that fosters good practices. First, we would expect that more principles of good practice that contribute to GP would exist at liberal arts colleges than at non-liberal arts colleges. Second, we would expect that students who attend liberal arts colleges have greater exposure to good practices as compared to students who attend non-liberal arts colleges. Third, we would expect that the effect of GP on student outcomes is greater at liberal arts colleges than at non-liberal arts colleges.

We found inconsistent evidence that liberal arts colleges instill an institutional ethos that fosters GP. Inconsistent with an ethos explanation, not all of the seven principles affect GP at liberal arts colleges. Further inconsistent with an ethos explanation, the same number of principles - active 
learning, student-faculty contact, time on task, and high expectations - similarly affects GP regardless of institution type. An advantage of SEM is it allows us to test formally whether the path coefficients from the principles of good practice to GP are the same across types of institutions. These findings mean that the same principles of good practice as well as their strength in association are the same for students who attend liberal arts and non-liberal arts colleges.

If we move beyond the question of whether the sheer number of principles that contribute to GP constitutes an institutional ethos that fosters GP to a question of a student's exposure to GP, then we can conceive of liberal arts colleges fostering such an ethos. We did indeed find evidence of an institutional ethos at liberal arts colleges. Consistent with past studies (Cruce et al., 2006; Pascarella et al., 2004), a student at a liberal arts college tends to receive greater exposure to the principles of good practice than a student at a non-liberal arts college. This positive relation between liberal arts colleges and the principles holds even after controlling for a student's gender, race, parental education, ACT scores, financial aid, initial major aspiration, precollege academic motivation, and outcome premeasures. Liberal arts colleges are conducive to good practices due to their smaller size, focus on student-faculty interactions, and research opportunities for undergraduates (Cech, 1999; Chickering \& Reisser, 1993; Pascarella et al., 2004; Seifert et al., 2010). Our results suggest that the institutional ethos of GP at liberal arts colleges has more to do with the exposure to such practices than the multiplying effect of having several good practices enacted.

We found that the effects of GP on students' orientation towards diversity, openness to diversity, and leadership development are larger at liberal arts colleges than at non-liberal arts colleges; although we found no moderating effects for cognitive development and inclinations. This finding is largely consistent with an institutional ethos explanation where the effect of GP on student outcomes is greater at liberal arts colleges than at non-liberal arts colleges. However, a commitment to foster good practices may also yield unintended consequences at liberal arts colleges, especially for those with less exposure to these practices. An institutional ethos that fosters good practices may create a supportive social psychological environment that influences student outcomes (Astin, 1999; Chickering \& Reisser, 1993; Cruce et al., 2006; Pascarella \& Terenzini, 2005). An implicit assumption is that students at institutions with this ethos would be exposed to these good practices. Yet, students are unequally exposed to these practices, even at colleges with an institutional ethos that promotes good practices. As a result, students with low exposure to good practices who attend colleges with an institutional ethos that fosters good practices may experience even greater losses to their learning than similar students who attend non-liberal arts colleges.

Social scientists have found similar patterns where certain students react more strongly to contextual norms and expectations on their schooling outcomes. For example, Correll (2001) examines how cultural beliefs about gender in self-assessments affect students' career-relevant decisions. In particular, she focuses on high school students' perceptions of their math and English competences and how these perceptions influence their decisions to persist on a path towards quantitative professions. Correll (2001) finds a positive female-math grade interaction on math selfassessment, which implies that female students rely more on their math performance feedback to raise their self-math assessment than male students. Stearns, Jha, and Potochnick (2013) show that white students are more sensitive to their academic profile than minority students in their four-year college attendance. In particular, the racialized meritocracy argument (Blau, 2003) states that the meritocratic ideal is racially constructed where white students are more subscribed to the meritocratic narrative than minority students. Stearns et al. (2013) find that minority students with midlevel rigor in their academic coursework are more likely to attend a four-year college than similar white students. Further consistent with a racialized meritocracy argument, educational expectations mediate a larger portion of the relation between academic coursework and college attendance for white students as compared to minority students. 
Finally, we found little evidence that the influence of GP on student outcomes differs by race, gender, and academic achievement. The exception is that the relation between GP and orientation towards diversity is stronger for male students at non-liberal arts colleges than female students at similar colleges. Prior studies show compensatory effects of good practices by student characteristics (Seifert et al., 2014; Seifert et al., 2010). However, our study differs from prior research in two ways. First, Seifert et al. (2010) examined the differential influence of liberal arts colleges on good practices by social background. In other words, their focus was on the differential exposure to good practices rather than the differential effect of good practices on student outcomes, which was our study's focus. Second, Seifert et al. (2014) considered the two-way interaction between good practices and student characteristics. Instead, we focused our interactions within institution type. Therefore, we were interested in whether, for example, the influence of GP on need for cognition differed for males and females attending liberal arts colleges.

\section{Conclusions}

Several higher education administrators and researchers have considered certain "good practices" of institutions as instrumental to improving student outcomes. A limitation of past studies is that they often do not consider the holistic way in which good practices influence student outcomes. In addition, there are few studies of which we are aware that systematically tests whether different institutions instill an ethos that fosters good practices. We address these limitations in this study and test Chickering and Gamson's (1987) seven principles of good practice with longitudinal multi-institution data. Instead of examining the unique effect of each principle on student outcomes, we simultaneously test which of the seven principles contribute to a global concept of good practices and the global effect of good practices on student outcomes.

There is inconsistent evidence that liberal arts colleges foster an institutional ethos that fosters good practices. On the one hand, the number of principles that affected GP was the same regardless of institution type. If an institutional ethos of good practices exists at liberal arts colleges, we would expect that more principles would go into a global concept of good practices. This was not the case. On the other hand, students attending liberal arts colleges tended to receive greater exposure to good practices than students attending non-liberal arts colleges. Furthermore, the effects of good practices on several student outcomes are stronger at liberal arts schools than at nonliberal arts schools.

There are several implications from our findings. Implementing these good practices in higher education remain important today as it did when Chickering and Gamson (1987) wrote their seminal paper almost thirty years ago because these practices can set the foundation for which students cultivate a liberal arts education. Human and financial resources may be difficult for higher education institutions to implement but good practices are responsive to purposeful interventions. For instance, student-faculty contact, time on task, active learning, and high expectations are practices and behaviors that faculty members are able to learn and implement in their classrooms.

At liberal arts colleges, it was their exposure to good practices rather than experiencing a larger collection of good practices that partly constituted an institutional ethos. Education administrators at regional and research universities should find ways that foster these good practices. Although there is evidence to show that some universities have implemented initiatives to create learning environments that foster good practices - such as learning communities, freshman interest groups, and honors programs - these initiatives may not provide learning conditions that cultivate good practices in a manner similar to that of liberal arts colleges (Seifert et al., 2010). Moreover, we found little evidence within institutions that the influence of GP on student outcomes differs by race, gender, and academic achievement. Education administrators can therefore focus more on equitable exposure to these good practices among students of different racial-ethnic backgrounds, gender, and achievement levels rather than focusing on the differential effects of these practices. 
Although there are several benefits for instilling an ethos of good practices, we remind readers of the potential negative consequences of such an ethos. The effect of GP on several student outcomes was greater at liberal arts colleges than at non-liberal arts colleges. It is important for administrators to remember that a push towards instilling an ethos of good practices may reward those who are exposed to these practices, but may doubly punish those who are not exposed to these practices. Some students who are uncomfortable engaging and interacting with faculty, for example, may have even greater losses to their learning in an institution with an ethos that fosters good practices.

Finally, administrators should consider implementing these good practices in graduate education. The vast majority of initiatives to instill these good practices have done so at the undergraduate level; there have been fewer efforts to engage the graduate student population (Pontius \& Harper, 2006). This lack of effort is unfortunate because the advising relationship between students and faculty, student engagement, and peer interactions are important determinants of persistence toward a graduate degree (Pontius \& Harper, 2006). Many of these predictors of graduate-school persistence resonate strongly with the principles of good practice. Before higher education administrators consider creating supportive environments for graduate and professional students, however, research is sorely needed that considers whether the principles of good practice influence a student's graduate education.

\section{Acknowledgements}

Second through fourth authors equally contributed to this paper and their names are listed alphabetically. An earlier version of this paper was presented at the 2013 Annual Meeting of the American Educational Research Association. This research is supported by a grant from the Center of Inquiry in the Liberal Arts at Wabash College to the Center for Research on Undergraduate Education at the University of Iowa. The opinions expressed are those of the authors and do not represent views of the Center of Inquiry in the Liberal Arts or the Center for Research on Undergraduate Education. The authors are grateful for helpful comments on earlier versions of the article from Ernest Pascarella, and the JSPTE editor and referees. Direct correspondence to Brian An, University of Iowa, 493 Lindquist Center North, Iowa City, IA 52242, United States. Telephone: 1-319-335-6390. Email: brian-an@uiowa.edu.

\section{References}

Acock, A. C. (2013). Discovering structural equation modeling using Stata (Revised edition). College Station, TX: Stata Press.

Allison, P. D. (2009). Fixed effects regression models. Thousand Oaks, CA: Sage Publications.

Arum, R., \& Roksa, J. (2011). Academically adrift: Limited learning on college campuses. Chicago: University Of Chicago Press.

Astin, A. W. (1999). How the liberal arts college affects students. Daedalus, 128, 77-100. doi: $10.2307 / 20027539$

Blaich, C., Bost, A., Chan, E., \& Lynch, R. (2004). Defining liberal arts education. Center of Inquiry at Wabash College. Crawfordsville, IN.

Blau, J. R. (2003). Race in the schools: Perpetuating white dominance? Boulder, CO: Lynne Rienner Press.

Bollen, K. A., \& Bauldry, S. (2011). Three Cs in measurement models: Causal indicators, composite indicators, and covariates. Psychological Methods, 16, 265-284. doi: 10.1037/a0024448

Cech, T. R. (1999). Science at liberal arts colleges: A better education? Daedalus, 128, 195-216. doi: $10.2307 / 20027545$ 
Center of Inquiry at Wabash College. (2011). Wabash National Study 2006-2009. Retrieved from http://www.liberalarts.wabash.edu/

Chickering, A. W., \& Gamson, Z. F. (1987). Seven principles for good practice in undergraduate education. AAHE Bulletin, 39, 3-7.

Chickering, A. W., \& Reisser, L. (1993). Education and identity (2nd ed.). San Francisco: Jossey-Bass.

Correll, S. J. (2001). Gender and the career choice process: The role of biased self-assessments. American Journal of Sociology, 106, 1691-1730. doi: 10.1086/321299

Cruce, T. M., Wolniak, G. C., Seifert, T. A., \& Pascarella, E. T. (2006). Impacts of good practices on cognitive development, learning orientations, and graduate degree plans during the first year of college. Journal of College Student Development, 47, 365-383. doi: 10.1353/csd.2006.0042

Ethington, C. A. (2000). Influences of the normative environment of peer groups on community college students' perceptions of growth and development. Research in Higher Education, 41, 703-722. doi: 10.1023/a:1007068604692

Freeman, J. E. (2002). Differences in teaching in a liberal arts college versus research university. In S. F. Davis \& W. Buskist (Eds.), The teaching of psychology: Essays in honor of Wilbert J. McKeachie and Charles L. Brewer (pp. 247-258). Mahwah, NJ: Lawrence Erlbaum Associates, Publishers.

Gillig, B., Roksa, J., \& Pascarella, E. T. (2013). Predicting change in academic motivation: Academic and social factors. Paper presented at the annual meeting of the Association for the Study of Higher Education, St. Louis.

Hanushek, E. A., Kain, J. F., \& Rivkin, S. G. (2009). New evidence about Brown v. Board of Education: The complex effects of school racial composition on achievement. Journal of Labor Economics, 27, 349-383. doi: 10.1086/600386

Hauser, R. M., Tsai, S. L., \& Sewell, W. H. (1983). A model of stratification with response error in social and psychological variables. Sociology of Education, 56, 20-46. doi: 10.2307/2112301

Hersh, R. H. (1999). Generating ideals and transforming lives: A contemporary case for the residential liberal arts college. Daedalus, 128, 173-194. doi: 10.2307/20027544

Howell, J. A., \& Eidson, D. R. (1985). The idea of an ideal liberal arts college. Lanham, MD: University Press of America.

Hu, S., \& Kuh, G. D. (2003). Diversity experiences and college student learning and personal development. Journal of College Student Development, 44, 320-334. doi: 10.1353/csd.2003.0026

Hughes, A. (2014, August 11). Essay on earning tenure at small liberal arts colleges, Inside Higher Ed.

King, P. M., Brown, M. K., Lindsay, N. K., \& Vanhecke, J. R. (2007). Liberal arts student learning outcomes: An integrated approach. About Campus, 12, 2-9. doi: 10.1002/abc.222

Kline, R. B. (2006). Reverse arrow dynamics: Formative measurement and feedback loops. In G. R. Hancock \& R. O. Mueller (Eds.), Structural equation modeling: A second course (pp. 43-68).

Greenwich, CT: Information Age Publishing.

Kuh, G. D., Pace, C. R., \& Vesper, N. (1997). The development of process indicators to estimate student gains associated with good practices in undergraduate education. Research in Higher Education, 38, 435-454. doi: 10.1023/a:1024962526492

Mueller, R. O., \& Hancock, G. R. (2010). Structural equation modeling. In G. R. Hancock \& R. O. Mueller (Eds.), The reviewer's guide to quantitative methods in the social sciences (pp. 371-383). New York: Routledge.

National Leadership Council for Liberal Education and America's Promise. (2007). College learning for the new global century: A report from the National Leadership Council for Liberal Education and America's Promise. Washington, DC: Association of American Colleges Universities National Leadership Council. 
Padgett, R. D., Salisbury, M. H., An, B. P., \& Pascarella, E. T. (2010). Required, practical, or unnecessary? An examination and demonstration of propensity score matching using longitudinal secondary data. New Directions for Institutional Research, 2010, 29-42. doi: 10.1002/ir.370

Pascarella, E. T., \& Terenzini, P. T. (2005). How college affects students: A third decade of research. San Francisco: Jossey-Bass.

Pascarella, E. T., Wang, J. S., Trolian, T. L., \& Blaich, C. (2013). How the instructional and learning environments of liberal arts colleges enhance cognitive development. Higher Education, 66, 569-583. doi: $10.1007 / \mathrm{s} 10734-013-9622-\mathrm{z}$

Pascarella, E. T., Wolniak, G. C., Cruce, T. M., \& Blaich, C. F. (2004). Do liberal arts colleges really foster good practices in undergraduate education? Journal of College Student Development, 45, 57-74. doi: $10.1353 / \mathrm{csd} .2004 .0013$

Pascarella, E. T., Wolniak, G. C., Seifert, T. A., Cruce, T. M., \& Blaich, C. F. (2005). Liberal arts colleges and liberal arts education: New evidence on impacts. ASHE Higher Education Report, 31, 1-148. doi: 10.1002/aehe.3103

Pontius, J. L., \& Harper, S. R. (2006). Principles for good practice in graduate and professional student engagement. New Directions for Student Services, 2006, 47-58. doi: 10.1002/ss.215

Raftery, A. E. (1995). Bayesian model selection in social research. Sociological Methodology, 25, 111-163. doi: $10.2307 / 271063$

Seifert, T. A., Gillig, B., Hanson, J. M., Pascarella, E. T., \& Blaich, C. F. (2014). The conditional nature of high impact/good practices on student learning outcomes. Journal of Higher Education, 85, 531-564. doi: $10.1353 /$ jhe.2014

Seifert, T. A., Goodman, K. M., Lindsay, N., Jorgensen, J. D., Wolniak, G. C., Pascarella, E. T., \& Blaich, C. (2008). The effects of liberal arts experiences on liberal arts outcomes. Research in Higher Education, 49, 107-125. doi: 10.1007/s11162-007-9070-7

Seifert, T. A., Pascarella, E. T., Goodman, K. M., Salisbury, M. H., \& Blaich, C. F. (2010). Liberal arts colleges and good practices in undergraduate education: Additional evidence. Journal of College Student Development, 51, 1-22. doi: 10.1353/csd.0.0113

Stearns, E., Jha, N., \& Potochnick, S. (2013). Race, secondary school course of study, and college type. Social Science Research, 42, 789-803. doi: 10.1016/j.ssresearch.2013.01.007

Stimpert, J. L. (2004). Turbulent times: Four issues facing liberal arts colleges. Change, 36, 42-49. doi: $10.2307 / 40165793$

Umbach, P. D., \& Kuh, G. D. (2006). Student experiences with diversity at liberal arts colleges: Another claim for distinctiveness. Journal of Higher Education, 77, 169-192. doi: 10.2307/3838736 


\section{Appendix A}

The structural equations shown below represent our baseline model. We use this model as a reference to evaluate other model specifications. In this model, social background $\left(\xi_{1}-\xi_{4}\right)$, academic $\operatorname{achievement}\left(\xi_{5}\right)$, financial assistance $\left(\xi_{6}\right)$, initial major aspirations $\left(\xi_{7}\right)$, pre-college academic motivation $\left(\xi_{8}\right)$, and outcome premeasures $\left(\xi_{9}-\xi_{14}\right)$, are allowed to influence each of the seven principles of good practice $\left(\eta_{1}-\eta_{7}\right)$. In other words, the first structural equation of the baseline model is

$$
\eta_{g}=\sum_{k} \gamma_{g k} \xi_{k}
$$

where $\eta_{g i}$ is the outcome of the $\mathrm{g}$ th principle of good practice $(\mathrm{g}=1, \ldots, 7) . \xi_{k i}$ denotes the value on the $\mathrm{k} t h$ independent variable $(\mathrm{k}=1, \ldots, \mathrm{K})$ and $\gamma_{g k}$ denotes estimated parameters. In addition to influencing the principles of good practice, precollege factors $\left(\xi_{1}-\xi_{14}\right)$ influence students' major or intended major in the liberal arts by their fourth year of college $\left(\eta_{9}\right)$.

Moreover, we specify that

$$
\eta_{8}=\beta_{8,1} \eta_{1}+\beta_{8,2} \eta_{2}+\beta_{8,3} \eta_{3}+\beta_{8,4} \eta_{4}+\beta_{8,5} \eta_{5}+\beta_{8,6} \eta_{6}+\beta_{8,7} \eta_{7}
$$

The model in equation 2 states that GP $\left(\eta_{8}\right)$ is captured by the seven principles of good practice, which are student-faculty contact $\left(\eta_{1}\right)$, cooperation among students $\left(\eta_{2}\right)$, active learning $\left(\eta_{3}\right)$, prompt feedback $\left(\eta_{4}\right)$, time on task $\left(\eta_{5}\right)$, high expectations $\left(\eta_{6}\right)$, and respect towards diverse talents and ways of learning $\left(\eta_{7}\right)$. Therefore, we are able to estimate the unique contribution of each principle on GP. We allow for the disturbances among the principles of good practice $\left(\eta_{1}-\eta_{7}\right)$ and college major $\left(\eta_{9}\right)$ to correlate freely, but do not specify how the variables are related to one another. Finally, student outcomes $\left(\eta_{y}\right)$ is influenced by $\operatorname{GP}\left(\eta_{8}\right)$, college major $\left(\eta_{9}\right)$, and precollege controls $\left(\xi_{k}\right)$

$$
\eta_{y}=\beta_{y, 8} \eta_{8}+\beta_{y, 9} \eta_{9}+\sum_{k} \gamma_{y k} \xi_{k}
$$




\section{Appendix B}

Dependent variable

Need for cognition. Enjoy engaging in effortful cognitive activities (18 items, alpha $=0.89$;

$1-5$ where 5 is strongly agree).

Socially responsible leadership. Leadership across several elements: consciousness of self, congruence, commitment, common purposes, collaboration, change and controversy with civility and citizenship (alpha $=0.84 ; 1-5$ where 5 is strongly agree).

Orientation towards diversity. Miville-Guzman Universality-Diversity measures students' awareness of similarities and differences of others ( 15 items, alpha $=0.80 ; 1-5$ where 5 is strongly agree).

Openness to diversity as well as the extent students enjoy being challenged by different perspectives ( 7 items, alpha $=0.87 ; 1-5$ where 5 is strongly agree).

Positive attitude towards literacy ( 6 items, alpha $=0.71 ; 1-5$ where 5 is strongly agree).

Critical thinking. Collegiate Assessment of Academic Proficiency critical thinking test measuring students' ability to clarify, analyze, evaluate, and extend arguments (alpha = $0.82 ; 49-73)$.

Liberal arts college and education

Attends a liberal arts college

$0.56 \quad 0.50$

Major or intended major in liberal arts in spring 2010 ( $1=$ liberal arts).

$0.64 \quad 0.48$

Principles of good practice

Student-faculty contact (Standardized) $(15$ items; alpha $=0.90)$

$-0.03 \quad 0.64$

Cooperation among students (Standardized) $(4$ items; alpha $=0.68)$

$0.00 \quad 0.66$

Active learning (Standardized) $(7$ items; alpha $=0.73$ )

$-0.02 \quad 0.62$

Faculty gives prompt feedback (Standardized) $(3$ items; alpha $=0.68)$

$-0.04 \quad 0.79$

Emphasizes time on task (Standardized) $(10$ items; alpha $=0.73)$

$-0.03 \quad 0.53$

Challenging classes and high faculty expectations (Standardized) $(7$ items; alpha $=0.82)$

$-0.04 \quad 0.66$

Independent study or a self-designed major $(1=$ yes $)$

$0.32 \quad 0.47$

Internship, practicum, field or co-op experience, or clinical assignment $(1=$ yes $)$

$0.68 \quad 0.47$

Research project with faculty outside of course or program requirement $(1=$ yes $)$

$0.33 \quad 0.47$

Precollege Characteristics

Student is an underrepresented minority

$0.13 \quad 0.34$

Student is female

$0.64 \quad 0.48$

At least one parent attained a bachelor's degree

$0.34 \quad 0.47$

At least one parent attained a post-bachelor's degree

$0.43 \quad 0.50$

Received scholarship or grant financial aid

$0.49 \quad 0.50$

ACT composite score

$27.29 \quad 4.29$

Precollege academic motivation ( 8 items, alpha $=0.69 ; 1-5$ where 5 is high motivation).

$3.60 \quad 0.53$

Precollege major aspiration in liberal arts $(1=$ liberal arts $)$

$0.42 \quad 0.49$ 
Pre-college need for cognition. See Dependent variable for description of items. $\quad 3.54 \quad 0.59$

Pre-college socially responsible leadership $\quad 4.00 \quad 0.43$

Pre-college orientation towards diversity $\quad 4.62 \quad 0.64$

$\begin{array}{lrr}\text { Pre-college openness to diversity } & 3.93 & 0.63\end{array}$

Pre-college attitude towards literacy $\quad 3.38 \quad 0.70$

$\begin{array}{lrr}\text { Pre-college critical thinking } & 63.93 & 5.23\end{array}$

Note: WNSLAE 2006. Sample size is 1,065 respondents

\section{Appendix C}

\section{Description of items for the principles of good practice}

\section{Item description ( $\mathrm{R}$ denotes respondent)}

1. Student-faculty contact (alpha $=0.90)$

1 Extent $\mathrm{R}$ agrees that non-classroom interactions with faculty have had a positive influence on career goals and aspirations

2 Extent $\mathrm{R}$ agrees that since coming to this institution, $\mathrm{R}$ has developed a close, personal relationship with at least one faculty member

3 Extent $\mathrm{R}$ agrees that non-classroom interactions with faculty have had a positive influence on intellectual growth and interest in ideas

4 Most faculty with whom $\mathrm{R}$ had contact are willing to spend time outside of class to discuss issues of interest and importance to students

5 Extent $\mathrm{R}$ agrees that non-classroom interactions with faculty have had a positive influence on personal growth, values, and attitudes

6 Extent $\mathrm{R}$ agrees that $\mathrm{R}$ is satisfied with the opportunities to meet and interact informally with faculty members

7 Most faculty with whom $\mathrm{R}$ had contact are interested in helping students grow in more than just academic areas

8 Most faculty with whom $\mathrm{R}$ had contact are genuinely interested in students

9 Most faculty with whom $\mathrm{R}$ had contact are genuinely interested in teaching

10 Most faculty with whom $\mathrm{R}$ had contact are outstanding teachers

11 R's quality of relationships with faculty

12 During current school year, how often has R discussed grades or assignments with an instructor

13 During current school year, how often has $\mathrm{R}$ discussed ideas from readings or classes with faculty members outside of class

14 During current school year, how often R worked with faculty on activities other than coursework (committees, orientation, student life activities)

15 During current school year, how often has $\mathrm{R}$ talked about career plans with a faculty member or advisor

\section{Cooperation among students $($ alpha $=0.68)$}

$1 \mathrm{R}$ participated in one or more study group outside of class

2 In R's classes, students taught each other in addition to faculty teaching 
3 Faculty encouraged $\mathrm{R}$ to participate in study groups outside of class

4 During current school year, how often has $\mathrm{R}$ worked with classmates outside of class to prepare class assignments

\section{Active learning (alpha $=0.73)$}

1 Extent $\mathrm{R}$ agrees that courses have helped $\mathrm{R}$ see the connections between intended career and how it affects society

2 How often $\mathrm{R}$ learned something that changed the way $\mathrm{R}$ understands an issue or concept

3 During current school year, how often has $\mathrm{R}$ worked on a paper or project that required integrating ideas or information from various sources

4 During current school year, how often has R put together ideas or concepts from different courses when completing assignments or class discussions

5 During current school year, how often R discussed ideas from readings or classes with others outside of class (students, family members, co-workers)

6 Extent R agrees that out-of-class experiences have helped R connect what was learned in the classroom with life events

7 Extent R agrees that out-of-class experiences have helped R translate knowledge and understanding from the classroom into action

\section{Prompt feedback $($ alpha $=0.68)$}

1 How often faculty checked to see if $\mathrm{R}$ had learned the material well before going on to new material

2 How often faculty informed $\mathrm{R}$ of level of performance in a timely manner

3 During current school year, how often has R received prompt written or oral feedback from faculty on academic performance

\section{Time on task (alpha $=\mathbf{0 . 7 3})$}

1 Frequency that course goals and requirements were clearly explained

2 Frequency that faculty had a good command of what they were teaching

3 Frequency that the presentation of material was well organized

4 Frequency that faculty were well prepared for class

5 Frequency that class time was used effectively

6 Time R spent synthesizing and organizing ideas, information, or experiences into new, more complex interpretations and relationships

7 Time spent analyzing basic elements of an idea, experience, or theory (examine a particular case or situation in depth and consider its components)

8 Time R spent applying theories or concepts to practical problems or in new situations

9 Number of hours per week R spends preparing for class

10 Time spent judging value of information, arguments, or methods (examine how others gather or interpret data and assess soundness of conclusions) 


\section{High expectations $($ alpha $=\mathbf{0 . 8 2})$}

1 How often students challenged each others ideas in class

2 The extent $\mathrm{R}$ agrees that courses have helped $\mathrm{R}$ understand the historical, political, and social connections of past events

3 How often faculty asked $\mathrm{R}$ to show how a particular course concept could be applied to an actual problem or situation

4 How often faculty asked $\mathrm{R}$ to argue for or against a particular point of view

5 How often faculty asked challenging questions in class

6 How often faculty asked $\mathrm{R}$ to point out any fallacies in basic ideas, principles, or points of view presented in the course

7 How often faculty challenged Rs ideas in class

\section{Respect towards diverse talents and ways of learning ( 3 binary indicators)}

$1 \mathrm{R}$ has done independent study or a self-designed major (or plans to before graduation)

$2 \mathrm{R}$ has done, or plans to do, a practicum, internship, field experience, co-op experience, or clinical assignment before graduation

$3 \mathrm{R}$ has worked on a research project with a faculty member outside of course or program requirements (or plans to before graduation)

\section{Biographies}

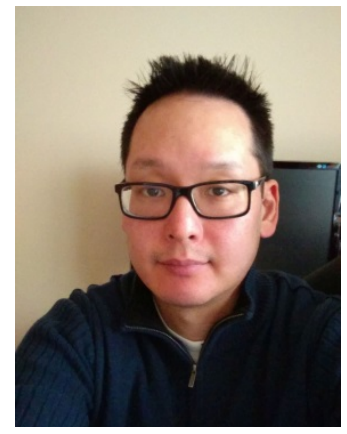

Brian P. An (Ph.D., Sociology, University of Wisconsin-Madison) is Assistant Professor of Educational Policy and Leadership Studies at the University of Iowa, and Faculty Associate for the Center for Research on Undergraduate Education. Before taking his position at Iowa, he was Postdoctoral Research Associate for the Center for Research on Educational Opportunity at the University of Notre Dame. Broadly, his research focuses on college choice, college access, and the impact of college on students. Particularly, his research concentrates on the role of accelerated programs (e.g., dual enrollment) on academic performance, college readiness, and degree attainment. His work also considers family influences on a student's transition from high school to college. Furthermore, he has conducted research on binge drinking, college athletics, study abroad, and collaborative learning.

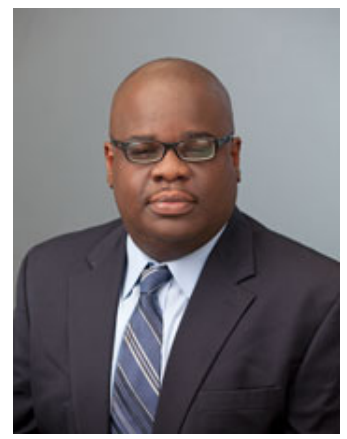

Eugene T. Parker (Ph.D., Educational Policy and Leadership Studies, University of Iowa) is Assistant Professor of Higher Education in the Educational Leadership and Policy Studies department at the University of Kansas. He is interested in matters of diversity, equity and inclusion as it relates to college students and organizations. His research has focused on the impact of collegiate experiences on college student outcomes, such as leadership and moral development. He also has research interests that centers on organizational and institutional theories, governance, leadership and structures. 


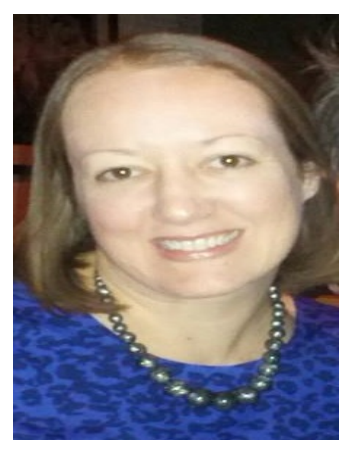

Teniell L. Trolian is a doctoral candidate in the Higher Education and Student Affairs Program at the University of Iowa. She earned an M.A. in College Student Personnel from Bowling Green State University and a B.A. in Sociology from Ohio State University before attending the University of Iowa. Her research interests include college experiences and outcomes and the influence of $\mathrm{K}-12$ experiences on college choice and college experiences.

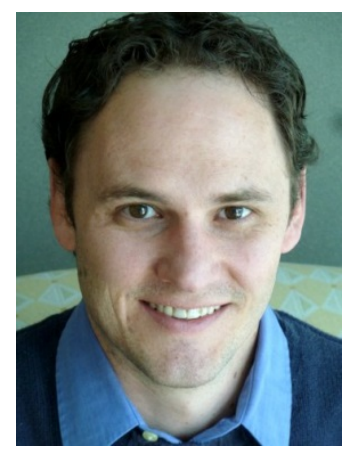

Dustin D. Weeden is Senior Policy Specialist with National Conference of State Legislatures's Education Program and co-staff coordinator for the Legislative Education Staff Network. His research tracks and analyzes legislation on higher education issues including affordability, finance, student loan debt, governance, technology transfer, and educational attainment. Additionally, he authors policy briefs, research reports, State Legislatures Magazine articles, and NCSL blog posts. He is a doctoral candidate in Higher Education at the University of Iowa. 